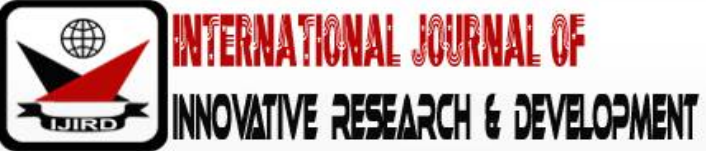

ISSN 2278 - 0211 (Online)

\section{Learning Gains on Selected Topics in Grade SIX Mathematics Using Concrete-Representational-Abstract Approach}

\begin{tabular}{|c|}
\hline Cherry B. Bangis \\
Teacher, Department of Education, Division of Malaybalay City, Philippines \\
Derren N. Gaylo \\
Instructor, College of Education, Bukidnon State University, Philippines
\end{tabular}

\begin{abstract}
:
This study determined the learning gains of Grade 6 learners in Mathematics lessons using Concrete-RepresentationalAbstract (CRA) approach. It was conducted in Matangpatang Elementary School, Schools Division of Malaybalay City, Philippines during the school year 2018-2019, that was participated by twenty learners. One group pretest-posttest quasiexperimental research design was used in the study. Lessons incorporating the CRA approach and researcher-made performance test were validated by a panel of experts in terms of content and content accuracy, clarity, and appropriateness. The results of their evaluation were taken into consideration in the revision of the developed lessons and test. Further, the revised performance test was tested for reliability and the result was 0.863 , which means that the instrument is consistent to assess the performance of learners. The data gathered were analyzed and interpreted using appropriate statistical techniques. Mean, standard deviation, frequency, percentage, and paired t-test were used. Results revealed that before Grade 6 learners were taught using CRA Approach, their academic performance was at Did Not Meet Expectations level. However, after they were taught using Concrete Representational Abstract Approach, they reached Fairly Satisfactory level. In addition, there is a significant difference in the learning gains of Grade 6 learners before and after they were taught using the said approach.
\end{abstract}

Keywords: CRA lessons, learning gains, grade six mathematic

\section{Introduction}

The ability to move between different representations is key to develop conceptual mathematical thinking and problem-solving skills (Dreher \& Kuntze, 2015). Cognitive and educational psychologists, as well as mathematics educators, have found that providing learners with multiple representations facilitates the development of schemas that ultimately cause an increase in the later transfer of solving new problems. Introducing a formulated problem that includes steps leading to a final solution provide learners with a mental model that can be used to form connections and facilitate transfer (Chi \& VanLehn, 2012). However, there is a need to strengthen these mental models through varied representations during instruction.

Multiple representations-based instructions are one of the differentiated approaches in teaching. Learners are given multiple options for taking in information in the varied representations. It is a process of visualizing and concretizing abstract concepts or symbols in Mathematics, as well as seeing the relationship between symbols and objects in different learning styles. In this approach, learners may be exposed to the construction of different alternative forms of representations on mathematical concepts, which later increases learners' retention of the lessons. This instructional approach encourages teachers to look for suitable representations that would fit learners' capabilities to motivate and help them understand the concept.

Considering learners' difficulties and misconceptions about the concepts in Mathematics, researchers suggested the use of multiple representations in the teaching and learning process (Tunc-Pekkan, 2015). The use of one mode of representation of a mathematical idea is not enough in helping learners to develop meaningful understanding (Duval, 2006). Through the use of multiple representations and the teacher's guidance, learners may be able to uncover abstract mathematical concepts by constructing meanings and understandings (Ministry of Education in Singapore, 2012).

In the Philippines, the conceptual framework of the present K to 12 Basic Education Curriculum considers Mathematics as a school subject that must be learned comprehensively and with much depth (Department of Education, 2016). The twin goals, critical thinking, and problem-solving, are to be achieved in with a planned curriculum content, well-defined skills and processes, desired values and attitudes, and appropriate tools suited to the diverse Filipino learners. However, the present National Achievement Test (NAT) results signify that the performance of the learners in the national scene falls below the target. The need to address this concern challenges the teachers to use effective strategies that may enhance learner's performance. 
As an elementary Mathematics teacher, the researcher witnessed many learners were having difficulty on understanding Mathematics concepts. All the more on applying those concepts in solving word problems. Struggles were evident at almost all grade levels. The various concepts of Mathematics seem hard to be grasped by elementary learners. In the grade level where the researcher is currently assigned, the learners know the different mathematical operations, however, their procedural knowledge did not lead them to answer the situational problems posed by the teacher. The link between the procedural knowledge towards conceptual knowledge should be established by the teacher. To do that, there is a need to make use of instructional approaches that would address the gap.

In Bukidnon, particularly in Malaybalay City Division, the mean percentage score results in Mathematics of the 2017 National Achievement Test in elementary level (Grade VI) was 34.05, which is in terms of three 21 st century skills namely problem solving, information literacy, and critical thinking. It falls short of the 75 mean percentage score goal of the Department of Education. As observed, the performance of Grade VI learners in Matangpatang Elementary School in the cited division was generally low. Teachers were challenged to find ways and means to address this problem and provide effective teaching and learning practices towards the learners. An approach that will improve the problem-solving skills, information literacy and critical thinking of learners, like Concrete-Representational-Abstract (CRA) approach, has to be investigated to fully uncover the role played of its three stages (concrete, representation, and abstraction) in developing the cited skills for the improvement of the NAT results.

In Singapore, one of the key instructional strategy in developing elementary Mathematics concepts is the concreterepresentational-abstract (CRA) approach, widely known as concrete-pictorial-abstract (CPA). It is very evident in the varied textbooks used in Singaporean schools. Singaporean mathematics is well known in the world for its evident results in Trends in International Mathematics and Science Study (TIMMS) and Programme for International Student Assessment (PISA).

CRA approach is a sequential three-step instructional approach that has been found to be highly effective in teaching Mathematics concepts. It has three stages: concrete, representational, and abstract. In the concrete stage, learners physically manipulate concrete objects to understand concepts and solve problems. The representational stage uses images to represent concrete objects for learners to further understand concepts and solve problems. On the abstract stage, numbers and symbols replace the images of concrete objects. CRA is a discovery-learning strategy that involves representation to help students' transition from procedural knowledge to conceptual knowledge (Sealander et al., 2012).

At present, the use of CRA approach is widely encouraged in elementary school due to the learning gains it brought to the Singaporean Mathematics classrooms fully documented as evident in there ranks in international Mathematics assessment and competitions. A growing body of research revealed on CRA approach in teaching Mathematics is effective in enhancing the performance of learners at risk of failure and those with learning disabilities (Hinton \& Flores, 2019; Bouck et al., 2016; Cook, 2013; Strickland \& Maccini, 2012; Witzel et al., 2008). However, there were limited studies that investigated the effects of CRA approach to regular elementary school learners.

Studies investigating the effectiveness of CRA approach through quasi-experimental designs found a significant difference from pretest to posttest results (Salingay\& Tan, 2018; Munawaroh \& Priatna, 2017; Akinoso, 2015; Miller \& Kaffar, 2011). However, the clear process from initial exposure of representations to the eventual acquisition of the mathematical concept was not documented in the existing literature (Ministry of Education in Singapore, 2012).

The mere presence of such representations during Mathematics lessons or the execution of the learning sequences cannot be assumed to lead to an automatic acquisition of the desired mathematical concepts. With these, the research sought to determine the learning gains brought by the CRA approach. It was conducted in a Grade VI Mathematics class in Matangpatang Elementary School, Schools Division of Malaybalay City in the school year 2018 - 2019.

\section{Framework of the Study}

The study is anchored on Bruner's (1966) Theory of Instruction. He posited that for learners to be self-sufficient problem-solvers, instruction should consist of a sequence of activities that increases their ability to grasp, transform and transfer the learning. It was cited that the sequence moves on three modes of representations, which start from enactive through iconic to symbolic stages. The enactive stage is more on manipulating objects like blocks, sticks, counters, and rods. The iconic stage entails the use of pictures, images, and drawings to represent the concept. The symbolic stage covers the abstract forms of the ideas presented. The concrete-representational-abstract approach evolved from the enactiveiconic-symbolic representations.

Kolb's (1984) four-stage cyclical Experiential Learning theory strengthens Bruner's idea, which is an extension of Dewey's (1938) Learning by Doing. He postulated that learning is the process where knowledge is formed by the transformation of experience, with four stages: (1) concrete experience; (2) observation and reflection; (3) forming abstract concepts; and (4) testing in new situations. One may begin at any stage but has to follow the stages on the sequence. Doing goes with the concrete experience, while observing happens in the reflective observation. Thinking happens on the abstract conceptualization and planning takes place in the testing and active experimentation phase.

Tomlinson's (2005) concept of differentiated instruction supports the theory of Bruner (1966). The proponent asserted that differentiated instruction is rooted in the belief that there is variability among any group of learners and that teachers need to adjust instruction accordingly (Tomlinson, 2005). In differentiating instruction, it is posited that learners learn best when their teachers accommodate the differences in their readiness levels, interests and learning styles to engage the students into meaningful learning. Tomlinson (2001) mentioned that lessons may be differentiated in terms of content, process, and products. It encompasses the preparation and delivery of instruction, techniques in managing classrooms, and prospects of learners' performance that considers the diversity and varied levels of readiness, interests, and learning profiles of the learners. 
Piaget's (1936) Cognitive Development Theory and Vygotsky's (1978) Zone of Proximal Development guided Bruner's claim. The cognitive development theory suggests that learner's ability to construct knowledge conform to cognitive developmental stages at their age. Preschool learners, usually at the pre-operational stage has the ability to represent objects and events but are unable to reverse their thinking. Elementary school learners, on the concreteoperational stage, has the ability to think logically but only in terms of concrete objects. On the other hand, secondary school learners are at the formal operational stage that they can now solve abstract problems and can hypothesize.

The teaching of Mathematics on the elementary level has to consider Piaget's stages of cognitive development. In addition, Vygotsky's concept of scaffolding is also necessary for this stage. Appropriate assistance must be given by the teacher or a more significant other to assist the elementary learners to accomplish the tasks on the zone of proximal development. The Concrete-Representational-Abstract (CRA) approach is one of the multiple representations-based instructions that is an effective way to enhance conceptual understanding, increase fluency in computing and develop problem-solving skills (Strickland \& Maccini,2013; Flores, 2010; Witzel, 2005).

Research suggests that the CRA approach may serve as an intervention to enhance the performance of learners in Mathematics (Hauser, 2004). It has three parts, the concrete, representational and abstract stages. In the concrete stage, the teacher starts the lesson by using concrete objects to model mathematical problems. In the representational stage, the teacher uses representations of objects like pictures, drawings, and images to model mathematical problems. In the abstract stage, the teacher represents the mathematics concept through symbols, where students are able to use abstract symbols to model mathematical problems.

\section{Statement of the Problem}

The study determined the learning gains of Concrete-Representational-Abstract (CRA) approach on Grade VI learners' performance in Mathematics. It was conducted at Matangpatang Elementary School, Schools Division of Malaybalay City during the School Year 2018-2019. Specifically, the study sought to answer the following questions:

- What is the performance of Grade VI learners in Mathematics before and after they were taught usingthe ConcreteRepresentational-Abstract (CRA) approach?

- Is there a significant difference in the learning gains of Grade VI learners in Mathematics before and after they were taught using the Concrete-Representational-Abstract (CRA) approach?

\section{Review of Related Studies}

CRA approach has been used as an instructional intervention in Mathematics. Several studies in Mathematics using CRA approach were documented in various grade levels and has been very effective when used to teach individuals with learning disabilities and learners at risk of failure in the United States of America.

In Michigan State University, researchers Bouck, Park and Nickell (2016) investigated the effects of using the CRA approach to teach middle school students in a self-contained mathematics class focused on functional-based mathematics to solve making change problems. Researchers used multiple probes across participants design to determine if a functional relation existed between the CRA strategy and students' ability to solve making change problems. The study consisted of five-to-eight baseline sessions, 9-11 intervention sessions, and two maintenance sessions for each student.Data were collected on the percentage of making change problems students solved correctly. The CRA instructional strategy was effective in teaching all four participants to correctly solve the problems; a functional relationship between the CRA approach and solving making the change with coins problems across all participants was found that CRA instructional approach can be used to support students with mild intellectual disability or severe learning disabilities in learning functional-based mathematics.

In Washington D.C., a study conducted by Strickland and Maccini (2012) examined the effects of the CRA approach on secondary school learners with learning disabilities ability to multiply linear algebraic expressions embedded within contextualized area problems. A multiple-probe design across three participants was used. Results indicated that the integration of the concrete manipulatives, sketches of manipulatives, and abstract notation with the support of a graphic organizer was an effective strategy to improve students' conceptual understanding and procedural fluency of multiplying two linear expressions.

Hinton and Flores (2019) investigated the effects of CRA instruction on the performance of elementary students across varied areas of need related to poor conceptual understanding and proficiency in completing tasks related to numbers and operations such as rounding, regrouping, and equivalent fractions. The researchers implemented multiple baselines across behaviors design for two students who were at risk for mathematics failure. A functional relation was found for CRA intervention and rounding, regrouping, and fraction concepts for the two students.

In a public high school in the southeast United States, Cook (2013) examined the effects of using concreterepresentational-abstract instruction on solving equations using inverse operations with high school students with mild intellectual disability. Students participated in the intervention individually for approximately five 45- minute sessions. Lesson times ranged from 20-minutes to 90-minutes. Using multiple probe experimental design, results indicated a functional relation between the abstract sequence of the CRA and students' ability to solve equations using inverse operations. Findings indicated a functional relation between the abstract sequence of instruction and students' ability to solve inverse operations. All students exhibited an immediate change in level from baseline to intervention after receiving the abstract lesson. During these lessons, students learn to move manipulatives and draw pictures to solve for unknown variables and to use opposite operations.

In Africa, particularly in South Africa, Mudaly and Naidoo (2015) explored how master mathematics teachers use the concrete-representational-abstract (CRA) sequence of instruction in mathematics classrooms. Data were collected 
from a convenience sample of six master teachers by observations, video recordings of their teaching, and semi-structured interviews. Data collection also included focus-group interviews with learners. Master teachers, considered expert teachers in their discipline, were selected by the Department of Education based on their many years of teaching experience; in addition, these selected master teachers taught at six different Dinaledi schools in KwaZulu-Natal. A key finding of this research demonstrated that the use of the CRA instructional sequence was paramount for the effective teaching of mathematics. This instructional sequence was found to be predetermined as well as intuitive.

In Nigeria, Akinoso (2015) conducted a quasi-experimental study utilizing concrete-representational-abstract instructional strategy in teaching Mathematics. The study adopted the pretest- posttest, control group design, participated by 191 senior secondary II students from four public schools purposively selected from two local government areas in Ibadan municipality. The experimental group was exposed to CRA and the control to modified conventional teaching strategy for 6 weeks. Instrument used was Students' Mathematics Achievement Test $(r=0.83)$. Two instructional guides on CRA and modified conventional teaching strategy were also used. Data were subjected to analysis of covariance. It was found out that the performance of the students taught with CRAISimproved significantly.

In Asian countries, like Indonesia, Munawaroh and Priatna (2017) determined the impact of the concreterepresentational-abstract approach and conventional for the mathematical connection ability of student at the 3rd grade in elementary school in Bahasa. The study was experimental research using a quasi-experimental design with a nonequivalent control group design. Results showed that the improvement of mathematical connection ability of students using the CRA approach was better than students who get conventional learning. CRA approach may be used as an alternative strategy to increase the mathematical connection ability of student in elementary school.

In the Philippines, Salingay and Tan (2018) inspected the effectiveness of the CPA approach to Grade 8 students of Bukidnon National High School in terms of students' attitude and performance. A quasi-experimental research design was used in this study, utilizing two intact classes. It was found out that students have a positive attitude towards success and usefulness of Math and undecided on their anxiety level, motivation level and on their confidence in learning Math during the pretest. During the post-test, all components remain the same instead to the confidence in learning Math of CPA group of students wherein form neutral during the pretest, it becomes positive during the post-test. The study also found out that the attitude of the students is comparable or has no significant difference. However, the performance in the post-test and retention test of the CPA group of students is significantly higher than the performance of a non-CPA group of students.

Milton et al. (2017) investigated the effects of alternating concrete-representational-abstract (CRA) multiplication and division instruction on students' mastery of unknown facts and on their conceptual understanding. Elementary learners who had failed to master all multiplication facts participated in the study. The researchers used a mixed method design, measuring accuracy and fluency of facts with multiple probes across students design and qualitative methods to capture changes in students' explanations of their computation. Qualitative results indicated differences in students' understanding of the operations.

Miller and Kaffar (2011) investigated the effectiveness of using the concrete-representational-abstract (CRA) teaching sequence with integrated strategy instruction for developing addition with regrouping competence among students with learning difficulties in mathematics. A total of 16 lessons were provided to 24 students during a six-week summer program. Students who received CRA with integrated strategy instruction out-performed comparison students on both computation and fluency.

Witzel (2005) compared student achievement in solving linear algebraic functions across two procedural approaches: a multisensory algebra model using a concrete-to-representational-to-abstract sequence of instruction (CRA) and a repeated abstract explicit instruction model. Out of 231 students who participated, the students who learned through the CRA model scored significantly higher on the post- and follow-up test. The success of the CRA model was consistent for students with a history of low, medium, and high math achievement.

The various literature and studies enlightened the researcher in different areas to be considered in the study. Most studies reviewed were useful in strengthening the researcher's claim about the CRA approach. Each related study reviewed fill in the missing link between learning gains and concrete-representational-abstract approach.

Methodology

This study utilized one group pretest- posttest research design. This type of research design that is most often utilized by behavioral researchers to determine the effect of a treatment or intervention on a given sample (Allen, 2017). This research design is characterized by two features: a single group of participants and assessment of a dependent variable before and after treatment.

The study was conducted at Matangpatang Elementary School, one of the sitios located in the mountainous area of Miglamin Malaybalay City. This study was participated in by Grade VI learners of Matangpatang Elementary School in the school year 2018-2019. There was only one section for Grade VI in the said school. Only one intact class was involved in the study and was composed of 20 learners. Fifty percent of the learners were 12 years old. Twenty-five percent comprises the 14 years old. Fifteen percent were 11 years old, five percent for the 13 years old and five percent for the 10 years old. The Grade VI learners in Matangpatang Elementary School had different levels of performance in Mathematics.

Lessons were developed by the researcher. The select five lessons were chosen on the least mastered skills in Grade VI Mathematics as identified by Mathematics teachers. With the aid of Task Analysis Blueprint (TAB), the development of lessons was guided accordingly. Lessons were written using the OSPEA format namely: Objectives, Subject Matter, Procedure, Evaluation, and Agreement. The usual lesson planning was followed, however, the CRA approach was incorporated in the lesson proper. It has three stages: concrete, representational, and abstract. A panel of experts, whose qualifications were Ph.D. and Masters degree holders, composed of a language expert, content expert and instructional 
material development expert. They evaluated the content and content accuracy, clarity and appropriateness of the developed lessons. Revisions were made in the developed lessons based on the experts' comments and suggestions.

The main research instruments used in the study was a researcher-made performance test. The researcher made a test to determine the academic performance of Grade VI learners. The test developed had 30 multiple choice items. The test was based on the Learning Competencies in the K to 12 Curriculum set by the Department of Education. The construction of the test was guided by a constructed Table of Specifications. The test was evaluated by a panel of experts before it was finalized. Experts' comments were utilized in the revision.A test try-out was conducted at Miglamin Annex National High School situated in Miglamin, Malaybalay City. Upon the approval of the school principal, 40 Grade 7 students took the performance test in Mathematics with the assistance of the Grade 7 Mathematics teacher.The reliability test result of the academic achievement test was 0.836 , which shows that the instrument is reliable, dependable and consistent to assess the learner's performance in Mathematics.

The scoring procedure followed the DepEd Order No. 8, s. 2015, also known as "Policy Guidelines on Classroom Assessment for the K to 12 Basic Education Program". In the 30-item multiple choice researcher-made achievement test, every correct answer was given one (1) point. The test was given as pretest and posttest. A pretest was administered before all the lessons started, while the posttest was given after all the lessons were presented to the students.Using the new guidelines in rating students' achievement effective school year 2015-2016, the raw scores were converted to percentage scores in order to ensure that the values are parallel to each other. To get the percentage score, divide the raw score with the highest possible score and multiply to $100 \%$. The percentage scores were transmuted using the transmutation table prescribed by the Department of Education to get the academic performance grade of the students. The scoring description follows:

\begin{tabular}{|c|c|c|c|}
\hline Range & Scale & Description & Qualifying Statement \\
\hline $26-30$ & $90-100$ & Outstanding & $\begin{array}{c}\text { Exceeds the core requirements in terms of knowledge, skills, } \\
\text { and understanding in Mathematics and can transfer them } \\
\text { automatically and flexibly through an authentic task. }\end{array}$ \\
\hline $23-25$ & $85-89$ & $\begin{array}{c}\text { Very } \\
\text { Satisfactory }\end{array}$ & $\begin{array}{c}\text { Develop the fundamental knowledge, skills, and understanding } \\
\text { in Mathematics and can transfer them automatically and } \\
\text { flexibly through an authentic task. }\end{array}$ \\
\hline $18-20$ & $75-79$ & $\begin{array}{c}\text { Fairly } \\
\text { Satisfactory }\end{array}$ & $\begin{array}{c}\text { Pevelop the fundamental knowledge, skills, and understanding } \\
\text { in Mathematics with little guidance from the teacher and can } \\
\text { transfer these understandings through an authentic task. } \\
\text { in Mathematics but needs help throughout the authentic task. }\end{array}$ \\
\hline $0-17$ & $\begin{array}{c}\text { Below } \\
75\end{array}$ & $\begin{array}{c}\text { Did Not Meet } \\
\text { Expectations }\end{array}$ & $\begin{array}{c}\text { Struggles with understanding the prerequisite and fundamental } \\
\text { knowledge and skills in Mathematics. }\end{array}$ \\
\hline
\end{tabular}

Table 1

Before the implementation of the study, the researcher first asked permission from the office of the Dean of the College of Education of Bukidnon State University for the conduct of the lessons. Upon the approval of the dean, a letter request addressed to the Schools Division Superintendent of DepEd- Malaybalay City for the conduct of the study was submitted. The approved letter request was then endorsed to the School Head of Matangpatang Elementary School. With the approval of the School Head, an orientation was conducted to the participants in the study.

The conduct of the lessons was personally done by the researcher. A pretest was conducted on the five lessons in Grade VI Mathematics. It covers plane and solid figures, finding the nth term and surface area, and calculating speed, distance, and time. In the implementation proper, the learners were taught in every lesson using the CRA approach.

The lesson proper starts with the concrete stage, where learners physically manipulated concrete objects to understand concepts and solve problems. It is followed by the representational stage, where images were used to represent concrete objects for learners to further understand concepts and solve problems. On the abstract stage, numbers and symbols replaced the images of concrete objects. After a series of lessons, a posttest was given. The data were then gathered for analysis and interpretation.

The data gathered were treated using appropriate statistical techniques. They were tabulated and organized into tables. To answer problems number 1, descriptive statistics like mean, standard deviation, frequency, and percentage were used to determine the performance of the learners in Grade VI Mathematics. To answer problem number 2, an inferential statistic named paired t-test was utilized to test the significant difference in the pretest and posttest performance in Mathematics of Grade VI learners.

\section{Results and Discussions}

Table 3 shows that the pretests mean score was lower than the posttest mean score result. However, their respective standard deviations indicated that the pretest scores were more dispersed than the posttest scores. Looking at the frequency, before the use of the CRA approach, the learners fall on the Did Not Meet Expectations and Fairly Satisfactory levels. After the intervention, the majority of the learners' performance met the expected competencies and some moved towards Very Satisfactory level. 


\begin{tabular}{|c|c|c|c|c|c|}
\hline \multirow{2}{*}{ Level of Proficiency } & \multirow{2}{*}{$\begin{array}{c}\text { Range of } \\
\text { Scores }\end{array}$} & \multicolumn{4}{|c|}{ Results } \\
\cline { 3 - 5 } & & \multicolumn{2}{|c|}{ Pretest } & \multicolumn{2}{c|}{ Posttest } \\
\cline { 3 - 5 } & & $\mathrm{f}$ & $\%$ & $\mathrm{f}$ & $\%$ \\
\hline Outstanding & $26-30$ & 0 & $0 \%$ & 0 & $0 \%$ \\
\hline Very Satisfactory & $23-25$ & 0 & $0 \%$ & 2 & $10 \%$ \\
\hline Satisfactory & $21-22$ & 0 & $0 \%$ & 3 & $15 \%$ \\
\hline Fairly Satisfactory & $18-20$ & 2 & $10 \%$ & 8 & $40 \%$ \\
\hline Did Not Meet Expectations & $0-17$ & 18 & $90 \%$ & 7 & $35 \%$ \\
\hline $\bar{x}$ & & \multicolumn{2}{|c|}{11.85} & & 18.45 \\
\hline SD & \multicolumn{2}{|c|}{3.67} & \multicolumn{2}{c|}{3.56} \\
\hline Qualitative Description & \multicolumn{2}{|c|}{ Did Not Meet Expectations } & Fairly Satisfactory \\
\hline
\end{tabular}

Table 2: Performance of Grade VI Learners in Mathematics

The frequency and percentage of pretest scores show that before the conduct of the study, the learnerparticipants least mastered the concepts. Pretest results indicate that the learners have poor academic achievement scores. The results suggest the need for effective learning approaches that will aid the improvement of learners' academic performance. It can be stated that when teachers do not incorporate effective learning approaches in the teaching and learning process, learners' academic achievement would be on the same level, which is low.

Usually, pretest results are low because they also experienced it most of the times in giving pretests. A similar finding in the pretest scores was revealed in a study conducted by Salingay and Tan (2018), wherein the Mathematics performance pretest scores are low. In terms of posttest, results presented using frequencies and percentages show that in the posttest a greater number of percentages of the learners' reached the Fairly Satisfactory level; while, thirty-five percent still remained Did Not Meet Expectation. A bigger number of the learners in the pretest did not meet the prescribed expectations; while, in the posttest majority successfully acquired the necessary expectations. Findings suggest that there was an increase in their mean scores in the test, which is attributed to the CRA approach.

Results signify that the use of concrete representational abstract approach in teaching grade six mathematics learners improved the learners' performance. Studies conducted by Salingay and Tan (2018), Munawaroh and Priatna (2017), Akinoso (2015), and Miller and Kaffar (2011) had similar findings with the present study. Based on learners' interviews, many claimed that they learn better because of the hands-on exercises using the manipulative. Learners did overcome some of their difficulty in the lessons by enjoying the varied activities instead of asking questions from their classmates and asking the teacher for more information.

As observed, all pupils participated in the lessons using the approach compared with the modular activities. The variation of teaching techniques, starting from the concrete phase using the manipulatives in the introduction of the topic, followed by a representational phase in the lesson proper and abstract phase using numbers and formulas and computations. Moreover, the attention is higher in degree compared when having modular activities. The interest shown by learners is more sustained when they enjoyed the varied activities. Pupils at first were hesitant with the changes in the teaching-learning process. Nevertheless, later on, they enjoyed the way lessons were being presented using the concrete representational abstract approach. A learner claimed that she is happy with the CRA stages. Such activities made her develop her communication skills and allowed her to made use of her own analysis. A lot of students raised their hands to say what's on their mind when compared before.

In every lesson, there were varied activities done on different stages. In the first lesson on plane figures, learners roam around the classroom and even went outside to find plane figures around. Based on observation, learners participated fully in the activity that they really touched and manipulated those objects they considered as plane figures. They even shared those figures in front of the class and described them as plane figures with justifications. These activities happened on the concrete stage. In the representation phase, learners made use of their drawing materials to illustrate the plane figures they encountered in the first activity. They even counted the number of sides and angles of each drawn plane figures. At the last part of the learning episode, abstraction stage, learners applied the concepts that they learned from the previous learning stages to the problem-solving activity. Many leaners answered the problems correctly. When asked about how they arrive with the answers, they shared that they were able to relate to the problems because they just draw it to comprehend the problems.

On the lesson about spatial figures, learners explored first the surrounding in the concrete stage, to identify the different objects that are a 3-dimensional figure present. They touched and pointed out the different parts of the spatial figures like the base, height, length, width, and sides. They were sharing the different figures they are holding with the group they were assigned. They tried their best to convince their groupmates that the objects they were holding were really considered as a spatial figure. On the representation stage, learners illustrated and labeled the different figures they considered as spatial figures. All of the illustrations presented by the learners were all correct. The learners were able to delineate spatial figures from plane figures. Further, on the abstract stage, learners solved problems involving finding the vertices, edges, and faces of the drawn spatial figures.

On surface area lessons, the learners brought three-dimensional figures in class and looked into if it has an area and shared it in class. In the representation stage, the learners constructed paper-made spatial figures. They cut it on the different edges and colored the different figures formed. They discovered that the colored figures represent the surface area. In the abstraction stage, the learners were able to solve problems on the surface area using derived formula. 
Algebraic patterns in the concrete stage were done with matchsticks activity. Learners find the 5th term of the given algebraic patterns. Using matchsticks, learners formed patterns from the first part up to the 5th term. In the representation stage, the learners illustrated the different formations in the concrete phase. They counted the number of matchsticks and tried to identify the sequence. In the abstraction stage, learners were able to formulate the nth term of the algebraic pattern when given set of patterns.

Speed, distance, and time lesson were conducted outside on their classroom in the concrete stage. Learners were given a task to throw stones on the designated area, then tally the distance traveled by stones and number of minutes it reached the ground. Then, they were asked to divide the distance with the time consumed on its travel in order to get the speed. On the representation phase, learners drew a map indicating their house and the location of the school. The path they used to walk to school was indicated. Whenever they were far from the school vicinity, they illustrated the route that public or private vehicle took. They had to indicate how many kilometers they had walked or passed by and the time they started and reached the place. On the other hand, word problems on finding the speed, distance or time were given to the learners to answer and use their abstraction.

The different stages of the CRA approach on the five lessons influenced an increase in their performance. Elia et al. (2010) explored the effects of pictures on children's spontaneous mathematical cognitive engagement. The story-related components of the pictures contribute to grasping the global story context of the text and the mathematics-related components help to understand the mathematical content of the story. The pictures have a representational or an informational function. The results showed that the picture book as a whole has the potential for cognitively engaging children. However, the pictures with a representational function were found to elicit mathematical thinking to a greater extent than the pictures with an informational function.

Table 2 shows the comparison results of the pretest and posttest results. It shows that there is a statistically significant difference in the learning gains between the pretest and the posttest. The data show that the use of CRA approach obtained a p-value which is lower than the significance level of 0.05 ; thus, the null hypothesis which states that there is no significant difference in the academic performance in Mathematics of Grade VI learners when taught using the Concrete Representational Abstract Approach. The difference must have resulted from the use of Concrete Representational Abstract Approach. The use of manipulatives, blocks and concrete activities gave more improvement in learners' performance.

\begin{tabular}{|c|c|c|c|c|}
\hline Pair & t-value & df & p-value & Remarks \\
\hline Pretest - Posttest & -8.581 & 19 & 0.000 & Significant \\
\hline
\end{tabular}

Table 3: Comparison of Pretest and Posttest Performance Scores of Learners

The findings of the present study corroborated with the results of Hinton and Flores (2019), Bouck et al. (2016), Milton et al. (2017), Mudaly and Naido (2015), Cook (2013), Strickland and Maccini (2012), Miller and Kaffar (2011) and Witzel (2005). CRA approach was tested to increase the performance and produced learning gains activity. As observed, the learners appreciated the activities, and with the use of manipulative materials they were able to broaden their understanding. Hands-on learning experience helped the learners more ready to understand concepts and enhance their self-confidence. It is easier for the learners to visualize math concepts and gain conceptual understanding using manipulative tools. The use of tangible objects made learning in mathematics fun.

A realization of the learners was established when they learned that matchsticks are an effective tool for teaching number facts. In addition, learning becomes interactive and engaging when learners are comfortable with their learning style through active learning experiences. Using manipulative materials are an advantage for the learners to visualize the concepts, construct meaning and integrate a more tangible understanding of abstract facts. Active learning experience helps the learners learn more visible than abstract and conceptual instruction.

The researcher found that during the activity, learners who were slow readers, kinesthetic learners and learners with limited English-language skills performed well on the activity. Their eagerness on the engagement was very obvious and the more they performed the hands-on activity the more they enhance their critical thinking. While the researcher was roaming around the activity venue, one academically struggling learner cited it is easier to learn algebraic patterns using matchsticks, it means he has understanding, clarifying and applying the mathematical concept. Working with other learners exposes learners to multiple ways of learning and working with mathematics.

On the representation stage, the learners experience the concrete stage bridge their understanding in the representational stage. Even if the learners are having difficulty to draw, they still think about brilliant ideas that they can use. Doing the representation stage, creativity was developed by the learners because they can interpret the problem. The well-illustrated problem manifested that they learned the concept and developed critical thinking. Encouragement to perform the mathematical operation is an important aspect that could help the learners love the subject. Through illustration, learners learned the basic ideas and help the learners to apply information in a new situation. Manipulatives provided another representation for the Mathematics being studied and can give learners ownership of their own learning. It also supported student engagement and differentiation.

With the foundation concepts from the concrete phase activities, learners had better understand in the abstract stage. Their learning already the basic concepts with the aid of the manipulatives in the concrete stage. In solving the problems in the abstract stage, the learners find it easier because they just relate it to the manipulative used. They enjoyed counting the matchsticks and discovered the concept of a sequence which is the opposite when the learning in a conventional learning instruction. By using these tangible objects, a connection between concrete and abstract levels of many Mathematics topics were established. Their motivation and willingness to ask questions, enthusiasm, and attention 
to the assigned task increased. Hands-on educational experiences moved learners beyond the traditional and passive practices of teaching and learning by incorporating creation, expression, and presentation of ideas.

\section{Conclusions and Recommendations}

Based on the aforementioned results and findings of the study, it can be concluded that the Grade VI learners possess the minimum knowledge, skills and core understanding in Mathematics but need help throughout the authentic task. Concrete- Representational- Abstract approach can help improve the performance of learners in Mathematics. Manipulatives, blocks and other concrete materials, as well as pictorial representations, may aid the learners to perform better.

It is recommended that elementary teachers use the concrete-representational-abstract approach in facilitating the teaching and learning process in Mathematics, especially on finding patterns and sequences, in order to help improve learner's academic achievement. In-service training and LAC sessions on the use of differentiated concreterepresentational-abstract approach could be initiated so that teachers would be able to apply it in their classrooms. Similar studies on the use of concrete representational abstract approach on least mastered lessons to improve learners' achievement may be conducted on a larger scope, different Grade level, another subject area and on a variety of research designs.

\section{References}

i. Akinoso, S. (2017). Teaching mathematics in a volatile, uncertain, complex and ambiguous (VUCA) world: The use of concrete-representational-abstract instructional strategy. Journal of the International Society for Teacher Education, 19(1), 97-107.Retrievedlast February 20, 2019 from https:// eric.ed.gov/ ?q=concrete+ representational+abstract\&id=EJ1177074.

ii. Allen, M. (2017). The sage encyclopedia of communication research methods (Vols. 1-4). Thousand Oaks, CA: SAGE Publications, Inc. doi: 10.4135/9781483381411

iii. Belenky, D. \& Nokes, T. (2009), Examining the Role of Manipulatives and Metacognition on Engagement, Learning, and Transfer. The Journal of Problem Solving, 2(2). Retrieved last February 20, 2019, from https:/ / docs.lib.purdue.edu/ cgi/ viewcontent.cgi? article=1061\&context=jps.

iv. Bouck, E., Park, J., \& Nickell, B. (2017). Using the concrete-representational-abstract approach to support students with intellectual disability to solve change-making problems. Research in Developmental Disabilities, 60, 24-36. doi:10.1016/ j.ridd.2016.11.006

v. Bruner, J. (1966). Toward a theory of instruction. Cambridge, MA, US: Harvard University Press.

vi. Chi, M. \& Van Lehn, K. (2012). Seeing deep structure from the interactions of surface features. Educational Psychologist, 47(3), 177-188. Retrieved last February 18, 2019 from http:/ / dx.doi.org/ 10.1080/ 00461520.2012.695709.

vii. Cook, J. ( 2013). The Effects of Concrete-Representational-Abstract Sequence of Instruction on Solving Equations using Inverse Operations with High School Students with Mild Intellectual Disability (Doctoral Dissertation). University of North Carolina at Charlotte. Retrieved last February 18, 2019 from http:/ / libres.uncg.edu/ir/ uncc/ f/ CeaseCook uncc 0694D 10492.pdf.

viii. Cross, S., Rogaten, J., Bektik, D.,Whitelock, D. \& Rienties, B. (2017). How do students understand and interpret learning gains?Perspectives from in-depth interviews of UK distance learners. In:SRHE Conference, 6-8 Dec 2017, Newport, Wales, UK.

Department of Education (2016). K to 12 Curriculum Guide in Mathematics (Grade 1 to Grade10). Retrieved last February 17, 2019 from http:/ / depedbohol.org/v2/wp-content/ uploads/ 2016/ 03/ Math-CG_with-taggedmath-equipment.pdf

ix. Dewey, J. (1938). Experience and Education. New York: Macmillan Company.

x. Dreher, A. \& Kuntze, S. (2015). Teachers' professional knowledge and noticing: The case of multiple representations in the mathematics classroom. Retrieved last February 11, 2019 from https:/ / www.researchgate.net/ publication/266833117_Teachers' professional_knowledge_and_noticing_The_cas e of multiple representations in the mathematics classroom.

xi. Duval, R. (200̄6). A Cognitive Ānalysis of Problems of Comprehension in a Learning of Mathematics. Retrievedlast February 18, 2019 fromhttp:/ / www.edumatec.mat.ufrgs.br/ artigos/ esm_2008_v68/ 5semiotic.pdf.

xii. Elia, I., Van den Heuvel-Panhuizen, M., \& Georgiou, A. (2010). The role of pictures in picture books on children's cognitive engagement with mathematics. European Early Childhood Education Research Journal, 18(3), 275-297. doi:10.1080/ 1350293x.2010.500054

xiii. Flores, M. (2010). Using the concrete-representational-abstract sequence to teach subtraction with regrouping to students at risk for failure. Remedial and Special Education, 31(3), 195207.https:/ / doi.org/ 10.1177/ 0741932508327467

xiv. Hauser ,J. (2009). Concrete-representational-abstract instructional approach. Access Center: Improving Outcomes for all Students K-8. Retrieved last February 19, 2019 from the http://www.k8accesscenter.org / training resources/ CRA Instructional_Approach.asp

xv. Hinton, V. \& Flores, M. (2019). The effects of the concrete representational-abstract sequence for students at risk for mathematics failure. Journal of Behavioral Education. doi: 10.1007/ s10864-018-09316-3.

xvi. Hughes, E. (2011). The Effects of Concrete-Representational-Abstract Sequenced Instruction on Struggling Learners Acquisition, Retention, and Self-Efficacy of Fractions (Doctoral Dissertation). Clemson University. 
Retrieved last February 19, 2019 from https://tigerprints.clemson.edu/cgi/viewcontent.cgi?article=1747\& context=all dissertations.

xvii. Kolb, D. A. (1984). Experiential learning: Experience as the source of learning and development (Vol. 1). Englewood Cliffs, NJ: Prentice-Hall.

xviii. Miller, S. \& Kaffar, B. (2011). Developing Addition and Regrouping Competence among Second Grade Students. Investigations in Mathematics Learning, 4(1), 25-51.Retrieved last February 20, 2019 from https:/ / eric.ed.gov/ ?q=concrete+representational+abstract \& pg=3\&id=EJ950987.

xix. Milton, J., Flores, M., Moore, A., Taylor, J., Burton, M. (2017). Using the Concrete-Representational-Abstract Sequence to Teach Conceptual Understanding of Basic Multiplication and Division. Learning Disability Quarterly, 42 (1), 32-45.Retrieved last February 20, 2019

fromhttps:/ / eric.ed.gov/ ?q=concrete+representational+abstract\&id=EJ1201264.

xx. Ministry Of Education (MOE) in Singapore (2012). https:/ / www.moe.gov.sg/ .

xxi. Mudaly, V. \& Naidoo, J. (2015). The concrete-representational-abstract sequence of instruction in mathematics classrooms. Perspectives in Education, 33 (1) , 1 42-56.

xxii. Munawaroh, A. \& Priatna, D. (2017). The impact of concrete representational abstract (CRA) approach for student's mathematical connection ability. Antologi UPI, 5(1), 57-67. Retrieved last February 20, 2019 from https:// www.neliti.com/ publications/ 240694/ the-impact-of-concrete-representational-abstract-cra-approachfor-students-mathe.

xxiii. Piaget, J. (1936). Origins of intelligence in the child. London: Routledge \& Kegan Paul.

xxiv. Salingay, R. \& Tan, D. (2018). Concrete-Pictorial-Abstract Approach On Students' Attitude And

xxv. Performance In Mathematics. International Journal of Scientific and Technology Research, 7(5). Retrieved last February 20, 2019 from http:// www.ijstr.org/ final-print/may2018/ Concrete-pictorial-abstract-Approach-OnStudents-Attitude-And-Performance-In-Mathematics.pdf.

xxvi. Sealander, K. A., Johnson, G. R., Lockwood, A. B., \& Medina, C. M. (2012). Concrete-Semiconcrete-Abstract (CSA) Instruction: A Decision Rule for Improving Instructional Efficacy. Assessment for Effective Intervention, 38(1), 53-65. https:/ / doi.org/ 10.1177/ 1534508412453164

xxvii. SEI-DOST \& MATHTED, (2011). Framework for philippine mathematics teacher education. Manila: SEI-DOST \& MATHTED.

xxviii. Strickland, T. \& Maccini, P. (2013). The effects of the concrete-representational-abstract integration strategy on the ability of students with learning disabilities to multiply linear expressions within area problems. Remedial and Special Education, 34(3), 142-153. https:// doi.org/ 10.1177/ 0741932512441712

xxix. Tomlinson, C. (2001). Differentiated instruction in the regular classroom. Retrieved June 26, 2016 from http:/ / www.inclusive schooling .com/ app/ uploads/articles/ Science_Think_Tac_Toe.pdf.

xxx. Tomlinson, C. (2005). Grading and differentiation: Paradox or good practice? Theory into Practice. Retrieved January 14, 2018 from https:// www.researchgate.net/ profile/ Carol Tomlinson2/ publication/ 249901118 Grading and Differentiation Paradox_or_Good_Practice/ links/ 55e84be408̄ae3e1218422c9f/ Grading-and-Differentiation-Paradox-or-Good Practice.pdf.

xxxi. Tunc-Pekkan, Z. (2015). An analysis of elementary school children's fractional knowledge depicted with circle, rectangle, and number line representations. Retrieved last February 18, 2019 from https:/ / www.researchgate.net/ profile/ Zelha Tunc Pekkan2/ publication/ 277328123.

xxxii. Vygotsky, L. (1978). Mind in society: The development of higher psychological processes. Cambridge, MA: Harvard University Press.

xxxiii. Witzel, B. (2005). Using CRA to Teach Algebra to Students with Math Difficulties in Inclusive Settings. Learning Disabilities: A Contemporary Journal, 3(2), 49-60.Retrievedlast February 20, 2019 from https:/ / eric.ed.gov/ ?q= concrete+representational + abstract $\&$ pg $=4 \& i d=E J 797683$ 